\title{
Clinical Presentation, Spectrum of Disease, and Natural History
}

\author{
Marco Merlo, Davide Stolfo, Thomas Caiffa, \\ Alberto Pivetta, and Gianfranco Sinagra
}

\section{Abbreviations and Acronyms}

CMR Cardiac magnetic resonance

CRT Cardiac resynchronization therapy

DCM Dilated cardiomyopathy

EMB Endomyocardial biopsy

HF Heart failure

KM Kaplan-Meier

LBBB Left bundle branch block

LGE Late gadolinium enhancement

LV Left ventricular

LVEF Left ventricular ejection fraction

LVRR Left ventricular reverse remodeling

RV Right ventricular

SCD Sudden cardiac death

M. Merlo $(\bowtie) \cdot$ G. Sinagra

Cardiovascular Department, Azienda Sanitaria Universitaria Integrata, Trieste, Italy e-mail: gianfranco.sinagra@asuits.sanita.fvg.it

D. Stolfo $\cdot$ T. Caiffa $\cdot$ A. Pivetta

Cardiovascular Department, Azienda Sanitaria Universitaria Integrata, University of Trieste (ASUITS), Trieste, Italy

e-mail: Davide.stolfo@asuits.sanita.fvg.it 
DCM: SPECTRUM OF DISEASE

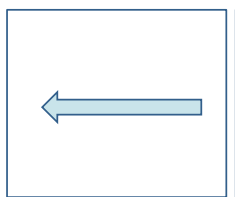

ETIOLOGY

- Genetic forms Inflammatory forms

Asymptomatic LV dysfunction

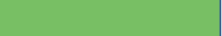

Arhythmias

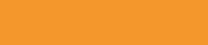

Genetic forms - Genetic forms

DIAGNOSIS
DIFFERENTIAL
DIAGNOSIS

- Sport screening - Arrhytmogenic

- Familial screening Cardiomyopathy
Inflammatory forms

- Alcohol

Chemoterapic

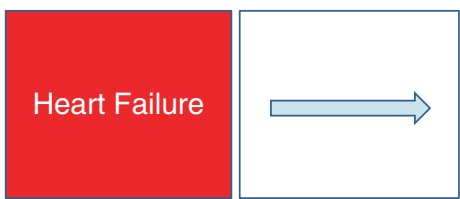

- Acute myocarditis

Fig. 6.1 Dilated cardiomyopathy: spectrum of disease

\subsection{Spectrum of Disease}

Before diagnosing dilated cardiomyopathy (DCM), it is necessary to exclude conditions with phenotypic overlap. A comprehensive integrated approach to patients with a newly diagnosed DCM is essential in order to achieve an accurate early prognostic stratification.

In many DCM individuals, there is a preclinical phase without cardiac expression that subsequently progresses toward mild cardiac abnormalities, such as isolated left ventricular (LV) dilatation, subtle systolic dysfunction, or arrhythmogenic features (ventricular or supraventricular arrhythmia or conduction defects) that can be observed in myocarditis [1,2] or in the early phase of genetic diseases [3]. The overt phase of systolic dysfunction is usually associated with LV dilatation, but this may be absent in some cases causing diagnostic confusion (described in Lamin A/C gene mutation carriers $[4,5]$ and also in some patients without a known genetic cause [6-8] (Fig. 6.1).

Thus, in this context every effort has to be made to obtain an accurate diagnosis (cardiac magnetic resonance (CMR), endomyocardial biopsy (EMB), biomarkers, etc.), with the aim to personalize patient management according to specific etiology.

The prognosis of DCM has improved in the course of the past years [9] with the use of evidence-based therapies, both pharmacological and non-pharmacological [10-12], and also due to the constant effort to diagnose this cardiomyopathy in the early stages (Figs. 6.2, 6.3, and 6.4) [13]. Identifying patients with DCM in an asymptomatic phase is equivalent to early diagnosis and guarantees a better longterm survival for the patients [14]. 
Fig. 6.2 Cause specific KM: survival free from all-cause mortality/heart transplant in IDCM patients according to the decade of enrolment. From Merlo et al., Long-term prognostic impact of therapeutic strategies in patients with idiopathic dilated cardiomyopathy: changing mortality over the last 30 years, Eur J Heart Fail, 2014; 16(3):317-24
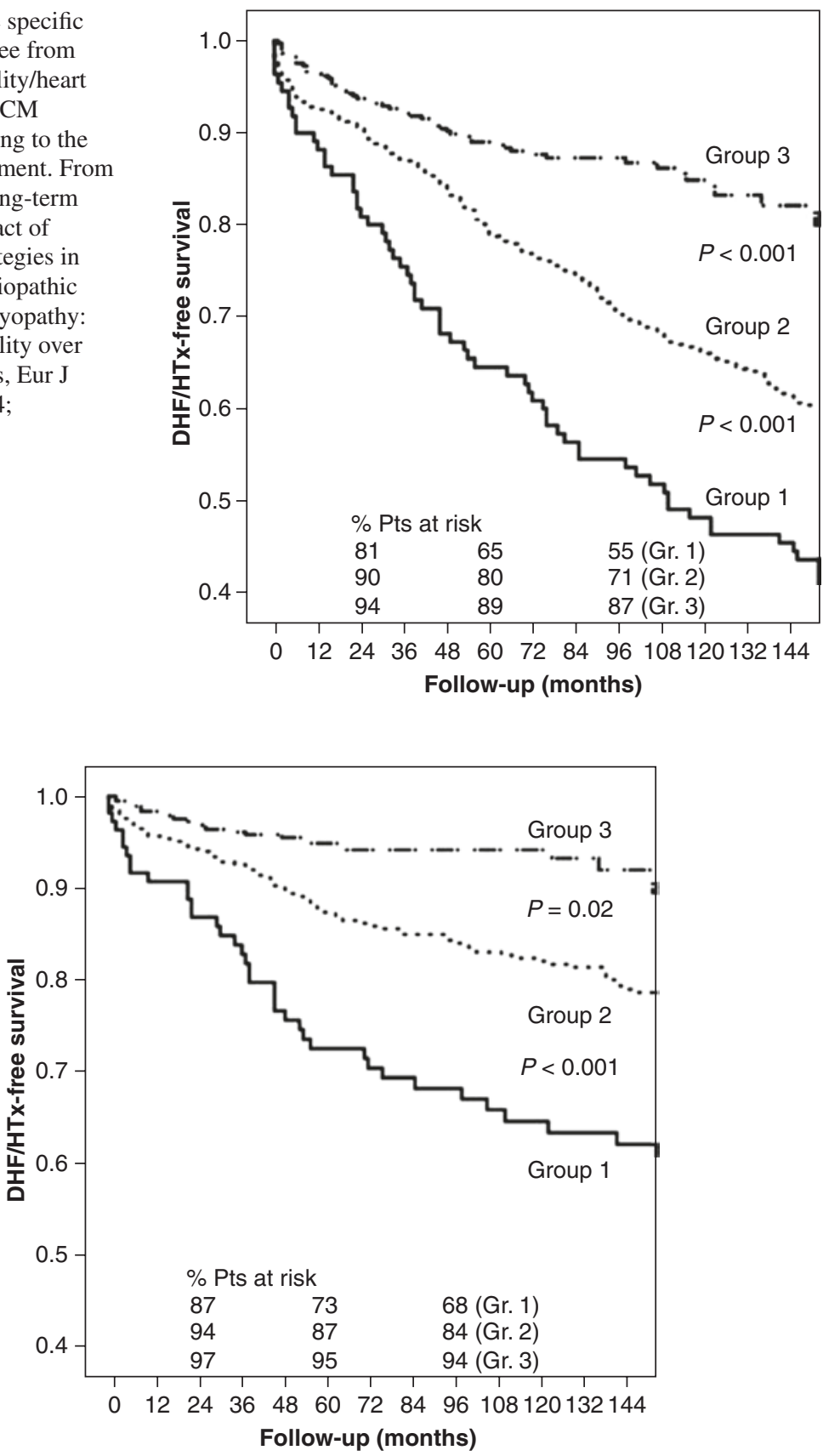

Fig. 6.3 Cause-specific KM curves: survival free from pump failure death/heart transplant in IDCM patients according to the decade of enrolment. From Merlo et al., Long-term prognostic impact of therapeutic strategies in patients with idiopathic dilated cardiomyopathy: changing mortality over the last 30 years, Eur J Heart Fail, 2014; 16(3):317-24 
Fig. 6.4 Cause-specific KM curves: survival free from sudden death in IDCM patients according to the decade of enrolment

From Merlo et al., Long-term prognostic impact of therapeutic strategies in patients with idiopathic dilated cardiomyopathy: changing mortality over the last 30 years, Eur J Heart Fail, 2014; 16(3):317-24

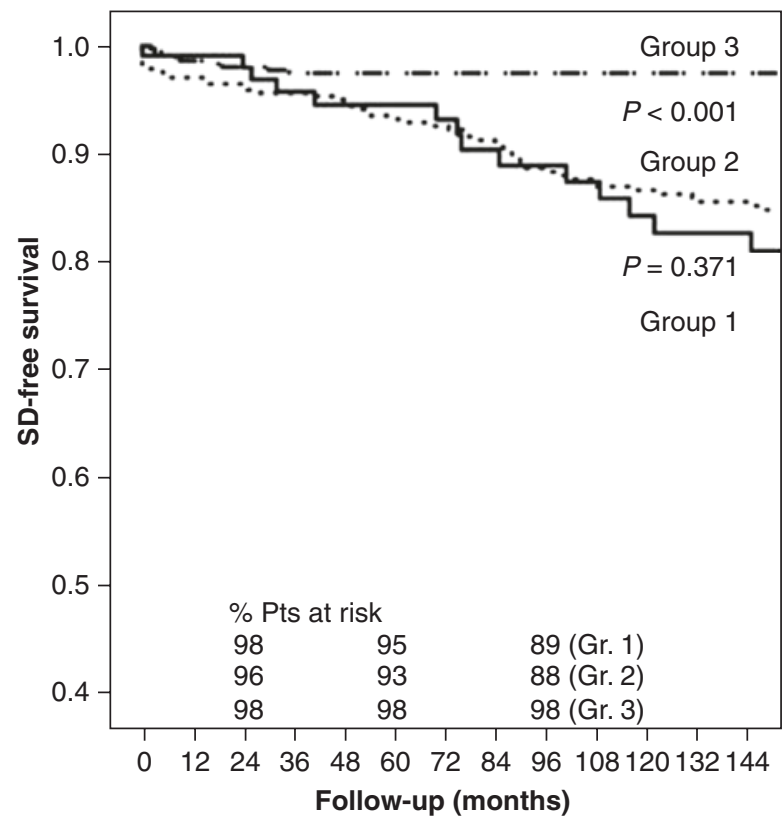

\subsection{Clinical Presentation}

In old series, initial symptoms of heart failure were present in $80 \%$ of patients with DCM [15]. These symptoms include excessive sweating, orthopnea, and fatigue after mild exertion. Abdominal discomfort, nausea, anorexia, and cachexia can be prominent in advanced cases. Circulatory collapse is the most severe manifestation of congestive heart failure. Thromboembolic events and, rarely, sudden cardiac death (SCD) might be the initial symptom, particularly in infants. Other symptoms include those related to ventricular or supraventricular arrhythmias (i.e., palpitations, syncope, fatigue).

In more recent years, however, the clinical presentation has somehow changed. In fact, the diagnosis often now occurs in asymptomatic individuals, mostly due to family and sports screening programs. Careful attention has to be made in evaluating the arrhythmic risk of these patients, since a non-negligible number of events can occur in the first months following the diagnosis.

Despite recent advances in medical treatment, LV dysfunction associated with signs of congestive heart failure (HF) is characterized by significant mortality [16]. Patients may progress through an asymptomatic phase of LV systolic dysfunction of various degrees, from mild to severe, before the development of overt HF [17-19]. LV dysfunction has frequently a progressive nature, and that is the reason for increasing interest regarding its preclinical state.

Most patients affected by DCM who present clinically with HF show symptoms and signs due to excess fluid accumulation (dyspnea, orthopnea, edema, pain from hepatic congestion, and abdominal discomfort due to ascites), sometimes associated with those due to a reduction in cardiac output (fatigue, weakness) [20]. 
In most patients with HF who require hospitalization, the reason for admission is volume overload. In clinical practice, four signs are commonly used to predict elevated filling pressures: jugular venous distention/abdominojugular reflux, presence of an S3 and/or S4, rales, and pedal edema. According to current international guidelines on HF $[21,22]$, the patient with HF can be clinically assessed along two basic axes-volume status ("dry" or "wet") and perfusion status ("warm" or "cold")—as a useful guide to therapy.

This approach has prognostic usefulness, particularly in assessing patients at discharge after admission for heart failure. For example, such patients discharged with a "wet" or "cold" profile experience worse outcomes (HR, 1.5; 95\% CI, 1.1-12.1; $P=0.017)$ compared with those discharged "warm and dry" (HR 0.9; 95\% CI, $0.7-2.1 ; P=0.5)[23]$.

In chronic presentations (months), symptoms as peripheral edema, abdominal distension, and anorexia may be more pronounced than dyspnea.

On the other hand, a decompensated chronic HF can lead to low-output symptoms.

Four major findings suggest severity of the cardiac dysfunction and low output: resting sinus tachycardia, narrow pulse pressure, diaphoresis, and peripheral vasoconstriction.

An irregularly irregular pulse is suggestive of atrial fibrillation which frequently accompanies HF. Pulsus alternans is a sign of severe left ventricular (LV) systolic failure. This phenomenon is characterized by evenly spaced alternating strong and weak peripheral pulses.

A laterally displaced apical impulse that is past the midclavicular line is usually indicative of LV enlargement.

An S3 gallop is associated with left atrial pressures exceeding $20 \mathrm{mmHg}$ and increased LV end-diastolic pressures ( $>15 \mathrm{mmHg})$.

An apical systolic murmur is associated with mitral regurgitation, often present in these patients.

Patients with chronic HF often develop secondary pulmonary hypertension, which can contribute to dyspnea as pulmonary pressures rise with exertion. These patients may also complain of substernal chest pressure, typical of angina. In this setting, elevated right ventricular end-diastolic pressure leads to secondary right ventricular subendocardial ischemia. Physical signs of pulmonary hypertension can include increased intensity of P2, a murmur of pulmonary insufficiency, a parasternal lift, and a palpable pulmonic tap (felt in the left second intercostal space) [20].

In patients with arrhythmic presentation, the onset of the disease may be the presence of palpitations, syncopal or near-syncopal episodes, or in some of them SCD. Thus, arrhythmic risk stratification is a major concern, as discussed in the following chapters.

\subsection{Natural History}

In the past, the prognosis of DCM was considered ominous [24], and the disease was frequently progressive to death due to HF or heart transplantation. 
By time the patients are diagnosed, they often have severe contractile dysfunction and remodeling of the ventricles, reflecting a long period of asymptomatic silent disease progression.

However, implementation of optimal pharmacological and non-pharmacological treatments has dramatically improved the prognosis of DCM [25] with an estimated survival free from death or heart transplantation up to $85 \%$ at 10 years $[13,26,27]$ (Table 6.1).

Table 6.1 Occurrence of major events in patients with DCM according to the decade of enrolment

\begin{tabular}{|c|c|c|c|c|c|c|}
\hline & \multirow{2}{*}{$\begin{array}{l}\text { First decade } \\
(1978- \\
1987)(110 \\
\text { patients })\end{array}$} & \multirow{2}{*}{\begin{tabular}{|l} 
Second \\
decade \\
$(1988-1997)$ \\
$(376$ patients $)$
\end{tabular}} & \multirow{2}{*}{$\begin{array}{l}\text { Third decade } \\
\text { (1998-2007) } \\
\text { (367 patients) }\end{array}$} & \multicolumn{3}{|c|}{$P$-value } \\
\hline & & & & \multicolumn{3}{|c|}{$\begin{array}{l}\text { First vs. second decade } \\
\text { first vs. third decade } \\
\text { second vs. third decade }\end{array}$} \\
\hline $\begin{array}{l}\text { Mean follow-up } \\
\text { (months) }\end{array}$ & $151 \pm 29$ & $153 \pm 82$ & $93 \pm 41$ & 0.389 & 0.03 & $<0.001$ \\
\hline $\begin{array}{l}\text { All-cause mortality/ } \\
\text { heart transplant, } n(\%)\end{array}$ & $77(70)$ & $178(47)$ & $53(14)$ & $<0.001$ & $<0.001$ & $<0.001$ \\
\hline $\begin{array}{l}\text { Incidence (events/100 } \\
\text { patients/year) }\end{array}$ & 5.6 & 3.9 & 1.9 & & & \\
\hline $\begin{array}{l}\text { Heart transplant, } \\
n(\%)\end{array}$ & $6(6)$ & $51(14)$ & $17(5)$ & 0.02 & 0.724 & $<0.001$ \\
\hline $\begin{array}{l}\text { Incidence (events/100 } \\
\text { patients/year) }\end{array}$ & 0.4 & 1.1 & 0.6 & & & \\
\hline $\begin{array}{l}\text { Cardiovascular death, } \\
n(\%)\end{array}$ & $57(52)$ & $91(24)$ & $18(5)$ & $<0.001$ & $<0.001$ & $<0.001$ \\
\hline $\begin{array}{l}\text { Incidence (events/100 } \\
\text { patients/year) }\end{array}$ & 4.1 & 2.0 & 0.6 & & & \\
\hline $\begin{array}{l}\text { Pump-failure death, } \\
n(\%)\end{array}$ & $38(35)$ & $32(9)$ & $6(2)$ & $<0.001$ & $<0.001$ & $<0.001$ \\
\hline $\begin{array}{l}\text { Incidence (events/100 } \\
\text { patients/year) }\end{array}$ & 2.8 & 0.7 & 0.2 & & & \\
\hline $\begin{array}{l}\text { Unexpected sudden } \\
\text { death, } n(\%)\end{array}$ & $16(15)$ & $51(14)$ & $9(3)$ & 0.793 & $<0.001$ & $<0.001$ \\
\hline $\begin{array}{l}\text { Incidence (events/100 } \\
\text { patients/year) }\end{array}$ & 1.2 & 1.1 & 0.3 & & & \\
\hline $\begin{array}{l}\text { Unknown cause death, } \\
n(\%)\end{array}$ & $13(12)$ & $31(9)$ & $16(4)$ & 0.338 & 0.004 & 0.014 \\
\hline $\begin{array}{l}\text { Incidence (events/100 } \\
\text { patients/year) }\end{array}$ & 1.0 & 0.7 & 0.6 & & & \\
\hline $\begin{array}{l}\text { Appropriate } \\
\text { intervention of ICD (\% } \\
\text { of Implanted patients) }\end{array}$ & 0 & 32 & 38 & $\mathrm{NC}^{*}$ & $\mathrm{NC}^{*}$ & 0.499 \\
\hline $\begin{array}{l}\text { Incidence (events/100 } \\
\text { implanted patients/ } \\
\text { year) }\end{array}$ & $\mathrm{NC}$ & 2.4 & 4.8 & & & \\
\hline
\end{tabular}

From Merlo et al., Long-term prognostic impact of therapeutic strategies in patients with idiopathic dilated cardiomyopathy: changing mortality over the last 30 years, Eur J Heart Fail, 2014; 16(3):317-24

$P$-value $<0.05$ are in bold type

ICD Implanted cardioverter-defibrillator, $N C$ not calculable

${ }^{*} P$-value not calculated; only two patients implanted with ICD in the first decade 
Moreover, the lower prevalence of comorbidities when compared to most patients with other forms of systolic LV dysfunction suggests that individuals with DCM tend to have fewer non-cardiovascular events [25]. In hypertensive heart disease, for example, there is a lower incidence of arrhythmic events and a greater competitive risk of non-cardiovascular events [28].

The improved outcomes in DCM are paralleled by a higher rate of LV reverse remodeling (LVRR): in recent years several studies revealed that almost $40 \%$ of patients experience a significant LVRR when treated with evidence-based pharmacological and device treatments [26].

From a pure mechanistic standpoint, LVRR is the result of either the removal of the noxious stimuli that triggered cardiac dysfunction or of the institution of therapies favorably interfering with the process of LV remodeling. Factors recognized to trigger or amplify LV remodeling include changes in myocardial wall tension and neurohormonal activation. Initially a compensatory process, the release of hypovolemic hormones (such as renin, antidiuretic hormone, and norepinephrine) eventually contributes to the progression of DCM, and pharmacologic therapies that reduce neurohormonal activation have been shown to promote LVRR [29].

The process of LVRR may take up to 2 years following diagnosis. The following aspects, evaluated at baseline and during follow-up, have been demonstrated as influencing the course and the prognosis of the disease and the likelihood of LVRR in the early stages and should be hence systematically assessed:

(a) Right ventricular function at diagnosis is an important prognostic feature in DCM [30]. The recovery of right ventricular function under therapy is frequent and can already be observed at 6 months. It precedes LVRR and is emerging as an early therapeutic target and an independent prognostic predictor [31]. Improvement in right ventricular function is also described in CRT recipients as a secondary expression of hemodynamic improvement very early after resynchronization, with consequently favorable survival rates [32]. In contrast, the development of right ventricular dysfunction during long-term follow-up is an expression of structural progression of the disease and portends a negative outcome [31].

(b) Functional mitral regurgitation conveys important prognostic implications. Moderate to severe mitral regurgitation at diagnosis or persistent despite optimal medical treatment or CRT is associated with poorer outcomes [32, 33]. Patients with DCM and hemodynamically important mitral regurgitation may require invasive therapeutic strategies such as percutaneous repair of the mitral valve, mechanical circulatory support, or even heart transplantation.

(c) Left bundle branch block (LBBB) is a frequent ECG marker at diagnosis and is negatively associated with the likelihood of LVRR [26]. Importantly the development of new LBBB during follow-up is a strong independent prognostic predictor of all-cause mortality [34]. 
(d) The onset of atrial fibrillation during the follow-up is a sign of structural progression of the disease and negatively impacts on the prognosis of these patients, despite effective treatments [35].

(e) In patients with DCM, the persistence of restrictive filing at 3 months after presentation is associated with a high mortality and transplantation rate. On the other hand, patients with reversible restrictive filling have a high probability of improvement and excellent survival. Thus, reassessment of these patients after 3 months of therapy gives additional prognostic information with respect to the initial evaluation [36].

The implications of these observations are that a multi-parametric approach to diagnosis and long-term follow-up, not limited to the LV systolic function and size alone, appear essential in order to improve the quality of clinical management of DCM patients [37].

In spite of this therapeutic success, emerging evidence suggests that some patients remain vulnerable to $\mathrm{SCD}$ and refractory HF requiring heart transplant or mechanical circulatory support [26].

Thus, the outcome of patients with DCM often remains unpredictable, and major adverse events may occur in the first months following the diagnosis [7, 38].

Furthermore, even when there is improvement in LV dysfunction, the potential for later decline in systolic function remains, despite uninterrupted treatment [37].

Sometimes LVRR is pronounced enough to result in a normalization of both LVEF and LV diameters, in a process that has been referred to as "apparent healing" or "myocardial remission" [39]. Nevertheless, in a retrospective observational study, only about $10 \%$ of DCM patients showed persistent apparent healing at long term (10 years), but the vast majority of them experienced a recurrence of LV dysfunction in a very long term, thus suggesting that the observed healing was only apparent and that true myocardial recovery is at most a rare event in DCM patients [40, 41].

This last issue emphasizes the pivotal role not only of an accurate and complete initial diagnostic evaluation but also of continuous and tailored, modulated therapy and individualized, long-term accurate surveillance in order to recognize and treat the first signs of late disease progression (Fig. 6.5).

Modern management of HF has increased the survival rates of DCM and has resulted in long periods of clinical stability [25, 42]. Consequently, affected patients followed for beyond 10-15 years are often encountered in clinical practice.

It has to be noted, in addition, that the patients should be continuously and critically reassessed, particularly in the presence of cardiovascular risk factors. Indeed, abrupt worsening of LV function or an increased ventricular arrhythmic burden can be caused not only by the DCM progression but also by the development of new co-pathologies. Therefore, the possible presence of coronary artery disease, hypertensive heart disease, structured valve disease, or an acute myocarditis should be systematically ruled out during the follow-up [37]. 


\section{NATURAL HISTORY OF DCM}

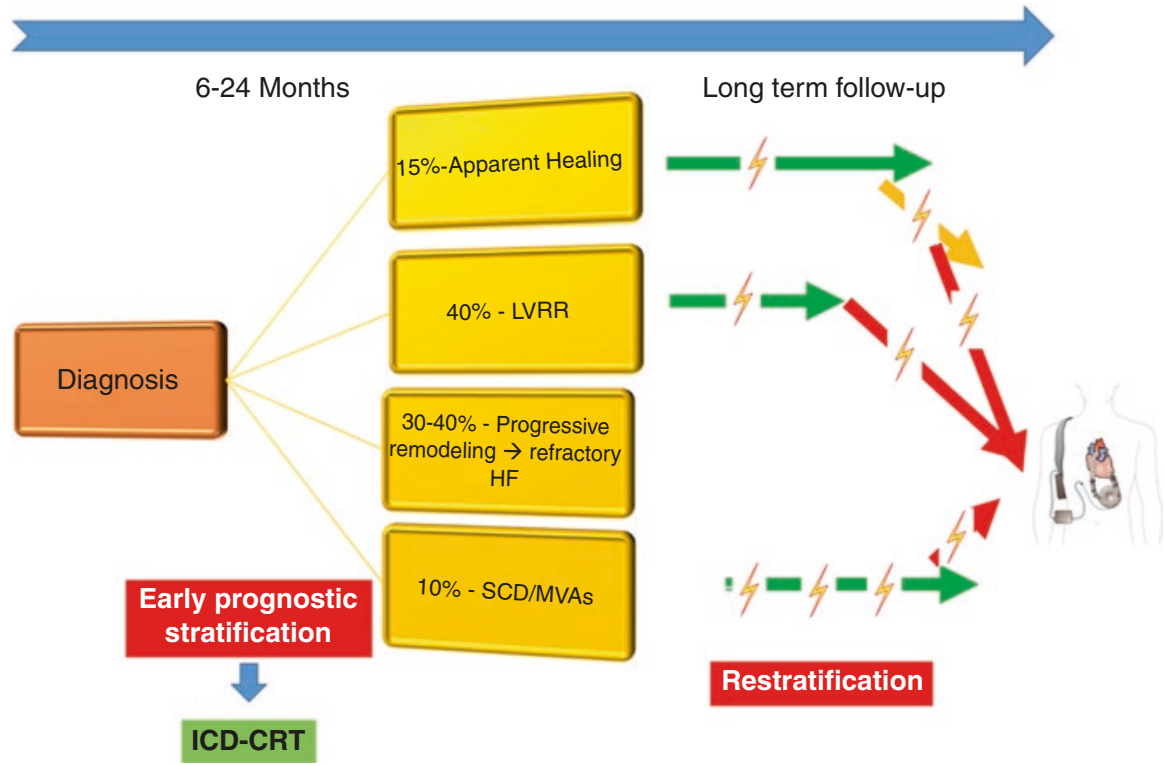

Fig. 6.5 Natural history of dilated cardiomyopathy. Early prognostic stratification and continuous restratification during long-term follow-up are fundamental in order to better identify those at higher risk of sudden cardiac death (arrow)

\section{References}

1. Caforio ALP, Pankuweit S, Arbustini E, Basso C, Gimeno-Blanes J, Felix SB, et al. Current state of knowledge on aetiology, diagnosis, management, and therapy of myocarditis: a position statement of the European Society of Cardiology Working Group on Myocardial and Pericardial Diseases. Eur Heart J. 2013;34(33):2636-48, 2648a-d.

2. Schultheiss H-P, Kuhl U, Cooper LT. The management of myocarditis. Eur Heart J. 2011;32(21):2616-25.

3. van Berlo JH, de Voogt WG, van der Kooi AJ, van Tintelen JP, Bonne G, Ben YR, et al. Metaanalysis of clinical characteristics of 299 carriers of LMNA gene mutations: do lamin A/C mutations portend a high risk of sudden death? J Mol Med (Berl). 2005;83(1):79-83.

4. van Tintelen JP, Tio RA, Kerstjens-Frederikse WS, van Berlo JH, Boven LG, Suurmeijer AJH, et al. Severe myocardial fibrosis caused by a deletion of the $5^{\prime}$ end of the lamin A/C gene. J Am Coll Cardiol. 2007;49(25):2430-9.

5. Sanna T, Dello Russo A, Toniolo D, Vytopil M, Pelargonio G, De Martino G, et al. Cardiac features of Emery-Dreifuss muscular dystrophy caused by lamin A/C gene mutations. Eur Heart J. 2003;24(24):2227-36.

6. Keren A, Gottlieb S, Tzivoni D, Stern S, Yarom R, Billingham ME, et al. Mildly dilated congestive cardiomyopathy. Use of prospective diagnostic criteria and description of the clinical course without heart transplantation. Circulation. 1990;81(2):506-17. 
7. Pinto YM, Elliott PM, Arbustini E, Adler Y, Anastasakis A, Bohm M, et al. Proposal for a revised definition of dilated cardiomyopathy, hypokinetic non-dilated cardiomyopathy, and its implications for clinical practice: a position statement of the ESC working group on myocardial and pericardial diseases. Eur Heart J. 2016;37(23):1850-8.

8. Felker GM, Shaw LK, O'Connor CM. A standardized definition of ischemic cardiomyopathy for use in clinical research. J Am Coll Cardiol. 2002;39(2):210-8.

9. Di Lenarda A, Pinamonti B, Mestroni L, Salvi A, Sabbadini G, Gregori D, et al. [How the natural history of dilated cardiomyopathy has changed. Review of the Registry of Myocardial Diseases of Trieste]. Ital Heart J Suppl. 2004;5(4):253-66.

10. Hunt SA, Baker DW, Chin MH, Cinquegrani MP, Feldman AM, Francis GS, et al. ACC/AHA guidelines for the evaluation and management of chronic heart failure in the adult: executive summary. A report of the American College of Cardiology/American Heart Association Task Force on Practice Guidelines (Committee to revise the 1995 Guide). J Am Coll Cardiol. 2001;38(7):2101-13.

11. Bardy GH, Lee KL, Mark DB, Poole JE, Packer DL, Boineau R, et al. Amiodarone or an implantable cardioverter-defibrillator for congestive heart failure. N Engl J Med. 2005;352(3):225-37.

12. Cleland JGF, Daubert J-C, Erdmann E, Freemantle N, Gras D, Kappenberger L, et al. The effect of cardiac resynchronization on morbidity and mortality in heart failure. N Engl J Med. 2005;352(15):1539-49.

13. Merlo M, Pivetta A, Pinamonti B, Stolfo D, Zecchin M, Barbati G, et al. Long-term prognostic impact of therapeutic strategies in patients with idiopathic dilated cardiomyopathy: changing mortality over the last 30 years. Eur J Heart Fail. 2014;16(3):317-24.

14. Aleksova A, Sabbadini G, Merlo M, Pinamonti B, Barbati G, Zecchin M, et al. Natural history of dilated cardiomyopathy: from asymptomatic left ventricular dysfunction to heart failure-a subgroup analysis from the Trieste Cardiomyopathy Registry. J Cardiovasc Med (Hagerstown). 2009;10(9):699-705.

15. Dec GW, Fuster V. Idiopathic dilated cardiomyopathy. N Engl J Med. 1994;331(23):1564-75.

16. Levy D, Kenchaiah S, Larson MG, Benjamin EJ, Kupka MJ, Ho KKL, et al. Long-term trends in the incidence of and survival with heart failure. N Engl J Med. 2002;347(18):1397-402.

17. Pfeffer MA, Braunwald E. Ventricular remodeling after myocardial infarction. Experimental observations and clinical implications. Circulation. 1990;81(4):1161-72.

18. Mann DL. Mechanisms and models in heart failure: a combinatorial approach. Circulation. 1999;100(9):999-1008.

19. McMurray JV, McDonagh TA, Davie AP, Cleland JG, Francis CM, Morrison C. Should we screen for asymptomatic left ventricular dysfunction to prevent heart failure? Eur Heart $\mathrm{J}$. 1998;19(6):842-6.

20. Colucci WS. Evaluation of the patient with suspected heart failure. https://www.uptodate.com/ contents/evaluation-of-the-patient-with-suspected-heart-failure.

21. Ponikowski P, Voors AA, Anker SD, Bueno H, Cleland JGF, Coats AJS, et al. 2016 ESC Guidelines for the diagnosis and treatment of acute and chronic heart failure: The Task Force for the diagnosis and treatment of acute and chronic heart failure of the European Society of Cardiology (ESC) Developed with the special contribution of the Heart Failure Association (HFA) of the ESC. Eur Heart J. 2016;37(27):2129-200.

22. Yancy CW, Jessup M, Bozkurt B, Butler J, Casey DEJ, Colvin MM, et al. 2017 ACC/AHA/ HFSA Focused Update of the 2013 ACCF/AHA Guideline for the Management of Heart Failure: A Report of the American College of Cardiology/American Heart Association Task Force on Clinical Practice Guidelines and the Heart Failure Society of America. Circulation. 2017;136(6):e137-61.

23. Chaudhry A, Singer AJ, Chohan J, Russo V, Lee C. Interrater reliability of hemodynamic profiling of patients with heart failure in the ED. Am J Emerg Med. 2008;26(2):196-201.

24. Gavazzi A, Lanzarini L, Cornalba C, Desperati M, Raisaro A, Angoli L, et al. Dilated (congestive) cardiomyopathy. Follow-up study of 137 patients. G Ital Cardiol. 1984;14(7):492-8. 
25. Merlo M, Pyxaras SA, Pinamonti B, Barbati G, Di Lenarda A, Sinagra G. Prevalence and prognostic significance of left ventricular reverse remodeling in dilated cardiomyopathy receiving tailored medical treatment. J Am Coll Cardiol. 2011;57(13):1468-76.

26. Zecchin M, Merlo M, Pivetta A, Barbati G, Lutman C, Gregori D, et al. How can optimization of medical treatment avoid unnecessary implantable cardioverter-defibrillator implantations in patients with idiopathic dilated cardiomyopathy presenting with "SCD-HeFT criteria?". Am J Cardiol. 2012;109(5):729-35.

27. Hazebroek MR, Moors S, Dennert R, van den Wijngaard A, Krapels I, Hoos M, et al. Prognostic relevance of gene-environment interactions in patients with dilated cardiomyopathy: applying the MOGE(S) classification. J Am Coll Cardiol. 2015;66(12):1313-23.

28. Bobbo M, Pinamonti B, Merlo M, Stolfo D, Iorio A, Ramani F, et al. Comparison of patient characteristics and course of hypertensive hypokinetic cardiomyopathy versus idiopathic dilated cardiomyopathy. Am J Cardiol. 2017;119(3):483-9.

29. Merlo M, Caiffa T, Gobbo M, Adamo L, Sinagra G. Reverse remodeling in dilated cardiomyopathy: insights and future perspectives. Int J Cardiol Heart Vasc. 2018;18:52-7.

30. Gulati A, Ismail TF, Jabbour A, Alpendurada F, Guha K, Ismail NA, et al. The prevalence and prognostic significance of right ventricular systolic dysfunction in nonischemic dilated cardiomyopathy. Circulation. 2013;128(15):1623-33.

31. Merlo M, Gobbo M, Stolfo D, Losurdo P, Ramani F, Barbati G, et al. The prognostic impact of the evolution of RV function in idiopathic DCM. JACC Cardiovasc Imaging. 2016;9(9):1034-42.

32. Stolfo D, Merlo M, Pinamonti B, Poli S, Gigli M, Barbati G, et al. Early improvement of functional mitral regurgitation in patients with idiopathic dilated cardiomyopathy. Am J Cardiol. 2015;115(8):1137-43.

33. Stolfo D, Tonet E, Barbati G, Gigli M, Pinamonti B, Zecchin M, et al. Acute hemodynamic response to cardiac resynchronization in dilated cardiomyopathy: effect on late mitral regurgitation. Pacing Clin Electrophysiol. 2015;38(11):1287-96.

34. Aleksova A, Carriere C, Zecchin M, Barbati G, Vitrella G, Di Lenarda A, et al. New-onset left bundle branch block independently predicts long-term mortality in patients with idiopathic dilated cardiomyopathy: data from the Trieste Heart Muscle Disease Registry. Eurospace. 2014;16(10):1450-9.

35. Aleksova A, Merlo M, Zecchin M, Sabbadini G, Barbati G, Vitrella G, et al. Impact of atrial fibrillation on outcome of patients with idiopathic dilated cardiomyopathy: data from the Heart Muscle Disease Registry of Trieste. Clin Med Res. 2010;8(3-4):142-9.

36. Pinamonti B, Zecchin M, Di Lenarda A, Gregori D, Sinagra G, Camerini F. Persistence of restrictive left ventricular filling pattern in dilated cardiomyopathy: an ominous prognostic sign. J Am Coll Cardiol. 1997;29(3):604-12.

37. Merlo M, Cannata A, Gobbo M, Stolfo D, Elliott PM, Sinagra G. Evolving concepts in dilated cardiomyopathy. Eur J Heart Fail. 2018;20(2):228-39.

38. Losurdo P, Stolfo D, Merlo M, Barbati G, Gobbo M, Gigli M, et al. Early arrhythmic events in idiopathic dilated cardiomyopathy. JACC Clin Electrophysiol. 2016;2(5):535-43.

39. Mann DL, Barger PM, Burkhoff D. Myocardial recovery and the failing heart: myth, magic, or molecular target? J Am Coll Cardiol. 2012;60(24):2465-72.

40. Merlo M, Stolfo D, Anzini M, Negri F, Pinamonti B, Barbati G, et al. Persistent recovery of normal left ventricular function and dimension in idiopathic dilated cardiomyopathy during long term follow up: does real healing exist? J Am Heart Assoc. 2015;4(1):e001504.

41. Adamo L, Perry A, Novak E, Makan M, Lindman BR, Mann DL. Abnormal global longitudinal strain predicts future deterioration of left ventricular function in heart failure patients with a recovered left ventricular ejection fraction. Circ Heart Fail 2017;10(6). pii: e003788.

42. Japp AG, Gulati A, Cook SA, Cowie MR, Prasad SK. The diagnosis and evaluation of dilated cardiomyopathy. J Am Coll Cardiol. 2016;67(25):2996-3010. 
Open Access This chapter is licensed under the terms of the Creative Commons Attribution 4.0 International License (http://creativecommons.org/licenses/by/4.0/), which permits use, sharing, adaptation, distribution and reproduction in any medium or format, as long as you give appropriate credit to the original author(s) and the source, provide a link to the Creative Commons license and indicate if changes were made.

The images or other third party material in this chapter are included in the chapter's Creative Commons license, unless indicated otherwise in a credit line to the material. If material is not included in the chapter's Creative Commons license and your intended use is not permitted by statutory regulation or exceeds the permitted use, you will need to obtain permission directly from the copyright holder. 